\title{
A RESEARCH ON MULTI-OBJECTIVE OPTIMIZATION OF THE GRINDING PROCESS USING SEGMENTED GRINDING WHEEL BY TAGUCHI-DEAR METHOD
}

\author{
Do Duc Trung \\ Faculty of Mechanical Engineering ${ }^{l}$ \\ doductrung@haui.edu.vn \\ Nhu-Tung Nguyen \\ Faculty of Mechanical Engineering ${ }^{l}$ \\ tungnn@haui.edu.vn \\ Dung Hoang Tien \\ Faculty of Mechanical Engineering ${ }^{l}$ \\ tiendung@haui.edu.vn \\ Ha Le Dang \\ Center of Mechanical Engineering ${ }^{l}$ \\ danghack@gmail.com \\ ${ }^{1}$ Hanoi University of Industry \\ 298 Cau Dien str., Bac Tu Liem District, Hanoi, 100000
}

\begin{abstract}
In this study, the mutil-objective optimization was applied for the surface grinding process of SAE420 steel. The aluminum oxide grinding wheels that were grooved by 15 grooves, 18 grooves, and 20 grooves were used in the experimental process. The Taguchi method was applied to design the experimental matrix. Four input parameters that were chosen for each experiment were the number of grooves in cylinder surface of grinding wheel, workpiece velocity, feed rate, and cutting depth. Four output parameters that were measured for each experimental were the machining surface roughness, the system vibrations in the three directions $(X, Y, Z)$. The DEAR technique was applied to determine the values of the input parameters to obtaine the minimum values of machining surface roughness and vibrations in three directions. By using this technique, the optimum values of grinding wheel groove number, workpiece velocity, feed-rate, cutting depth were 18 grooves, $15 \mathrm{~m} / \mathrm{min}, 2 \mathrm{~mm} / \mathrm{stroke}$, and $0.005 \mathrm{~mm}$, respectively. The verified experimental was performed by using the optimum values of input parameters. The validation results of surface roughness and vibrations in $X, Y, Z$ directions were $0.826(\mu \mathrm{m}), 0.531(\mu \mathrm{m}), 0.549(\mu \mathrm{m})$, and $0.646(\mu \mathrm{m})$, respectively. These results were great improved in comparing to the normal experimental results. Taguchi method and DEAR technique can be applied to improve the quality of grinding surface and reduce the vibrations of the technology system to restrain the increasing of the cutting forces in the grinding process. Finally, the research direction was also proposed in this study.
\end{abstract}

Keywords: Surface Grinding, Segmented Grinding Wheel, Taguchi, Dear, Surface Roughness, Vibration.

DOI: $10.21303 / 2461-4262.2021 .001612$

\section{Introduction}

Using a discontinuous grinding wheel (slotted and segmented wheel) was a promising solution in improving the efficiency of the grinding process $[1,2]$. Using slotted grinding wheel could reduce the cutting heat by $40 \%$ to $80 \%$ compared with conventional grinding wheels [3]. Using segmented grinding wheel could reduce the cutting force by up to $30 \%$ compared with conventional grinding wheels [4]. Both surface roughness and cutting force when using segmented grinding wheels have a smaller value than when using conventional grinding wheel $[5,6]$. Some recommendations when using a slotted aluminum oxide grinding wheel have also been proposed: surface roughness will have a minimum value when the number of grooves on the grinding wheel was18 (grooves) [7], the cutting force is minimized when the grooves in the grinding wheel were 20 (grooves) [8].

Surface roughness is often a common parameter that was chosen for evaluating the efficiency of machining in general, and grinding in particular $[9,10]$. Research to find the solutions to 
reduce surface roughness when grinding with conventional grinding wheel has been published in many studies. However, studies on surface roughness when grinding with a segmented grinding wheel were very limited. The studies that are performed to improve the surface quality when using the segmented grinding wheel for each different material were necessary.

In the machining processes, vibration is often studied through two methods: theoretical modeling method and experimental planning method. The theoretical modeling method has a wider application ability, but the number of input parameters is quite large, it is quite difficult to implement [11]. The experimental planning method is quite easy to perform because the number of input parameters is small [12-14]. However, this method is only applicable to each specific case. The above methods are aimed to predict the vibrations, cutting force, and surface roughness in the machining process to improve the quality of machining, and reduce the time and cost of the machining process.

The vibrations of the grinding machine spindle, even in very small amplitudes, also have a significant effect on the depth of the cut of the grinding grain on the machining surface, thereby affecting grinding productivity, surface quality and influence on the uneven wear phenomenon of the grinding wheel $[3,13-15]$. The spindle vibration of the grinder consists of forced and spontaneous (self-vibrating) vibrations [16]. The forced vibration is transmitted by external factors. The factors causing forced vibration can be mentioned as grinding wheel imbalance, bearing error, assembly error, etc. [17].

Self-vibrating is the vibration that occurs during grinding, which is highly dependent on the uniformity of the work material, cutting conditions, and the grinding wheel properties [13, 14]. Compared with the forced vibrations, the reduction of spontaneous vibrations is much more advantageous, this can be accomplished by changing some of the factors that affect on it, such as selection of the suitable cutting conditions, improvement of the clamp system, etc. [13, 18]. However, so far, it seems that the determination of the value of the cutting parameter to reduce the vibrations of the grinder spindle when using a segmented grinding wheel has not been mentioned by any studies. The aim of research that was presented in this paper was determination of the optimal value of several machining parameters to ensure that both surface roughness and self-vibrations are of small value.

This study selected the combination of Taguchi method and Data Envelopment Analysis based Ranking (DEAR) technique. The reason this combination method was chosen is because the experimental design according to the Taguchi method has the advantage of allowing a small number of experiments to be performed with a large number of input parameters, especially it is very suitable when having not much information of the research subjects [19-21]. The grinding process using a segmented grinding wheel is a case where there are too less information about the study subjects, so it is very suitable when using the Taguchi method to design experiments. DEAR technique showed an excellent efficiency in determining the optimal value of technology parameters in the machining processes, which has been performed in a simple methodology [22]. This method that was evaluated has been more effective than some other methods [23-25].

\section{Multi-objective optimization using DEAR technique}

The aim of this research was determination of the input parameters to obtain the minimum values of machining surface roughness and vibration amplitudes in $X, Z, Y$ directions. The DEAR technique that was used to solve optimization problem consisted of the steps as the following [25-27].

- Determine the weights $(w)$ for each response for all experiments. Weight of response is the ratio between response at any trial to the summation of all responses.

- Transform the data of response into weighted data by multiplying the observed data with its own weight.

- Divide the data as smaller the better with smaller the better.

- Treat this value as multi response performance index $(M R P I)$.

$$
\begin{gathered}
M R P I=W_{R_{a}} \cdot R_{a}+W_{A_{x}} \cdot A_{x}+W_{A_{y}} \cdot A_{y}+W_{A_{z}} \cdot A_{z} ; \\
W_{R_{a}}=\frac{R_{a}}{\sum R_{a}}
\end{gathered}
$$




$$
\begin{aligned}
& W_{A_{x}}=\frac{A_{x}}{\sum A_{x}} ; \\
& W_{A_{y}}=\frac{A_{y}}{\sum A_{y}} ; \\
& W_{A_{z}}=\frac{A_{z}}{\sum A_{z}} .
\end{aligned}
$$

For each input parameter, at any of the investigated levels that the MRPI is the smallest value is considered to be the best level. Subtract the maximum value of the MPRI from the minimum value of the $M R P I$, the input parameters that has the subtraction value of $M R P I$ is the largest among the selected input parameters is considered to have the greatest influence on the output parameters [25-27].

\section{Material and Method}

\section{1. Experimental Machine and Grinding Wheel}

The grinding machine (APSG-820/2A) that was made in Taiwan was used to perform the experimental research. The machine is capable of infinitely level adjusting the workpiece velocity and the feed-rate through the hydraulic pump system. Cutting depth is adjusted by vernier with precision of $0.005 \mathrm{~mm}$ (each line of vernier is $0.005 \mathrm{~mm}$ ).

Three aluminum oxide grinding wheels that were used with the sign of WA46J7V1A. The external diameter, thickness, and hole diameter of grinding wheels were $180 \mathrm{~mm}, 31.75 \mathrm{~mm}$, and $13 \mathrm{~mm}$, respectively. Three grinding wheels were grooved on the cylinder surface with number of the grooves of 15, 18, and 20, respectively. Each groove was semicircle with the diameter of $12 \mathrm{~mm}$ as shown in Fig. 1.
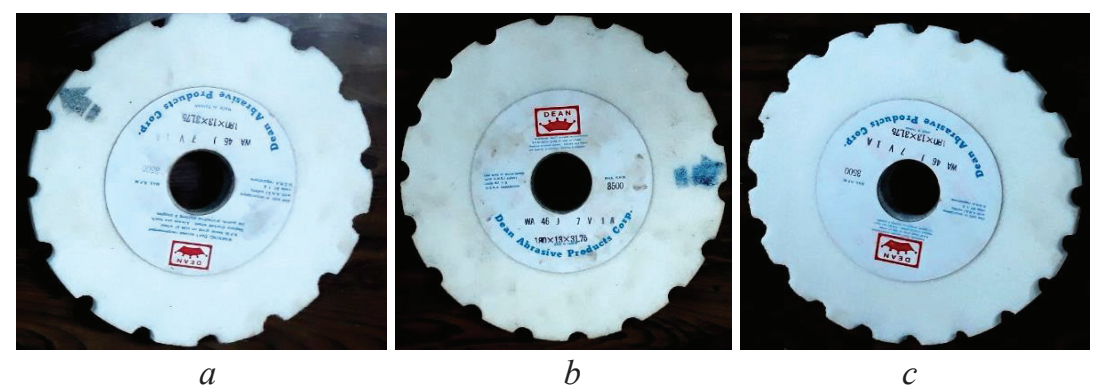

Fig. 1. Experimental segmented grinding wheels: $a-15$ grooves, $b-18$ grooves, $c-20$ grooves

To eliminate the effect of the grinding wheel wear on the output parameters, before conducting each experiment, the grinding wheel was dressed using a dressing tool with a diamond grain. The parameters of the grinding wheel dressing conditions include the wheel dressing depth of $0.01 \mathrm{~mm}$, the wheel dressing feedrate of $100 \mathrm{~mm} / \mathrm{min}$, the number of wheel dressing times of 3 times.

\section{2. Experimental Workpiece}

The SAE420 steel was used to conduct the experiments. This steel that was made in USA has the chemical composition as listed in Table 1. According several Standard, the equivalent sign of SAE420 steel are described in Table 2. The properties of SAE420 were described in Table 3. The length, width, and height of workpieces were $60 \mathrm{~mm}, 40 \mathrm{~mm}$, and $10 \mathrm{~mm}$, respectively as shown in Fig. 2.

Table 1

Chemical composition of SAE420 steel

\begin{tabular}{ccccc}
\hline $\mathbf{C}$ & $\mathbf{S i}$ & $\mathbf{M n}$ & $\mathbf{C r}$ & $\mathbf{S}$ \\
\hline 0.42 & 1.00 & 1.00 & 13.00 & 0.005
\end{tabular}


Table 2

Equivalent symbol of SAE420 steel of according several Standard

\begin{tabular}{cccccccccc}
\hline USA & Russia & Germany & Japan & France & England & Europe & Italy & Spain & China \\
\hline SAE & GOST & DIN & JIS & AFNOR & BS & EN & UNI & UNE & GB \\
420 & $3 X 13$ & 1.4028 & SUS420J2 & $410 F 21$ & $420 S 45$ & 1.4028 & GX30Cr13 & F.3403 & 3 Cr13
\end{tabular}

Table 3

The properties of SAE420 steel

\begin{tabular}{ccccccc}
\hline $\begin{array}{c}\text { Density } \\
\left(\mathbf{g} / \mathbf{c m}^{\mathbf{3}}\right)\end{array}$ & $\begin{array}{c}\text { Electrical Resis- } \\
\text { tivity }(\boldsymbol{\mu} \mathbf{\Omega} \mathbf{c m})\end{array}$ & $\begin{array}{c}\text { Thermal Conduc- } \\
\text { tivity }(\mathbf{W} / \mathbf{m} / \mathbf{K})\end{array}$ & $\begin{array}{c}\text { Coefficient of Thermal } \\
\text { Expansion }(\boldsymbol{\mu m} / \mathbf{m} / \mathbf{K})\end{array}$ & $\begin{array}{c}\text { Modulus of } \\
\text { Elasticity }(\mathbf{M P a})\end{array}$ & $\begin{array}{c}\text { Specific Heat } \\
(\mathbf{K J} / \mathbf{k g} / \mathbf{K})\end{array}$ & $\begin{array}{c}\text { Rockwell } \\
\text { Hardness }\end{array}$ \\
\hline 7.74 & 55 & 24.9 & 10.2 & $200 \times 10^{3}$ & 0.46 & $B 88$
\end{tabular}

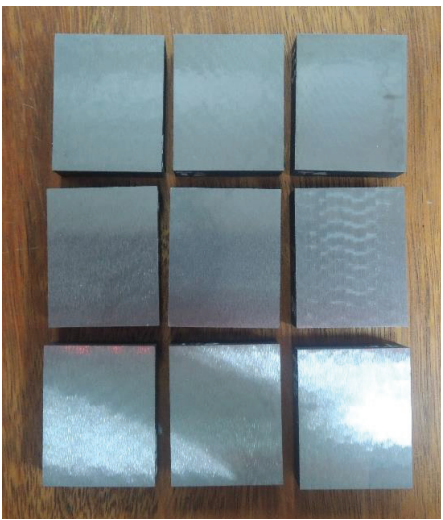

Fig. 2. Experimental workpieces

SAE420 steel that is a common steel is used for the manufacturing of the products in the shipbuilding, petroleum, chemical technology, food processing, and medical industries. etc. In the above products, many products need to be machined the important surfaces by grinding method. However, up to now, it seems that there has not been any published research on grinding this steel with a segmented grinding wheel. Therefore, the results of this study will have certain contributions to grinding technology in general and to grinding technology of this steel in particular.

\section{3. Experimental Design}

In this study, the Taguchi method was applied to design the experimental matrix. Four input parameters that were chosen for each experiment were the number of grooves in cylinder surface of grinding wheel, workpiece velocity, feed-rate, and cutting depth. The experimental matrix was design by using the Minitab software, and this matrix was stored in Table 4.

The experimental matrix that is designed according to the Taguchi method is used in this study because this method allows to perform with many input parameters, but the required number of experiments to perform is not much. For example in this study, there are 4 input parameters, each parameter has 3 value levels, but the number of experiments is only 9. Meanwhile, if compared with the design of the experimental matrix in the form of full orthogonality with 4 input parameters, the number of experiments are 17 experiments (including 16 experimental points at the origin and at least 1 experimental point at the center). On the other hand, a prominent advantage of the experimental method according to the Taguchi method is that it is possible to select the input parameters in a qualitative form (not quantitative form). Furthermore, in the Taguchi method, the values of the input parameters also need not be followed by the rule that the value of mid-level is equal to the average of the two low and high levels. With the number of grooves in the grinding wheel are 15, 18, and 20 showing that 18 is not the average of 15 and 20, it shows that the design of the experimental matrix according to the Taguchi method is the most suitable choice in this study. 
Table 4

Taguchi L9 based OA design

\begin{tabular}{ccccccccc}
\hline \multirow{2}{*}{ No. } & \multicolumn{3}{l}{ Coded levels } & \multicolumn{5}{c}{ Actual values } \\
\cline { 2 - 8 } & $\boldsymbol{Z}$ & $\boldsymbol{V}$ & $\boldsymbol{f}$ & $\boldsymbol{t}$ & $\boldsymbol{Z}$ (grooves) & $\boldsymbol{V}(\mathbf{m} / \mathbf{m i n})$ & $\boldsymbol{f}(\mathbf{m m} / \mathbf{s t r o k e )}$ & $\boldsymbol{t}(\mathbf{m m})$ \\
\hline 1 & 1 & 1 & 1 & 1 & 15 & 10 & 2 & 0.005 \\
2 & 1 & 2 & 2 & 2 & 15 & 15 & 3 & 0.010 \\
3 & 1 & 3 & 3 & 3 & 15 & 20 & 4 & 0.015 \\
4 & 2 & 1 & 2 & 2 & 18 & 10 & 2 & 0.015 \\
5 & 2 & 2 & 3 & 3 & 18 & 15 & 4 & 0.005 \\
6 & 2 & 3 & 1 & 1 & 18 & 20 & 2 & 0.010 \\
7 & 3 & 1 & 3 & 3 & 20 & 10 & 4 & 0.010 \\
8 & 3 & 2 & 1 & 1 & 20 & 15 & 2 & 0.015 \\
9 & 3 & 3 & 2 & 2 & 20 & 20 & 3 & 0.005
\end{tabular}

\section{4. Measurement System}

MITUTOYO-Surface test SJ-210 surface roughness tester was used to measure the machining surface roughness of the workpiece. The evaluation length was fixed at $0.8 \mathrm{~mm}$. The surface roughness was measured perpendicular to the cutting velocity direction and repeated three times following three repeated times of each cutting test. The average value of surface roughness that was measured three consecutive times was used for analysis and evaluation.

The vibration measurement system that included the acceleration sensor Type 4525-B-001, the data processing box, and the PULSE software was used to measure the system vibrations. For each experiment, the vibrations of system were measured simultaneously in three directions $(X, Y, Z)$. The detail is illustrated in Fig. 3.

The accelerometer is mounted on the grinding wheel guard. In each experiment, the vibration components will be measured in a 5-second interval. During this interval time, the software on the computer will display a graph of the vibration components during the time when the grinding wheel cutting and uncutting into the workpiece. However, during data processing, only the part of the graph of vibration during the time when the grinding wheel cutting into the workpiece is used, and in each experiment, the value of the vibration components is calculated as the its average value in this stage (the stage when grinding wheel cutting into the surface of the workpiece).

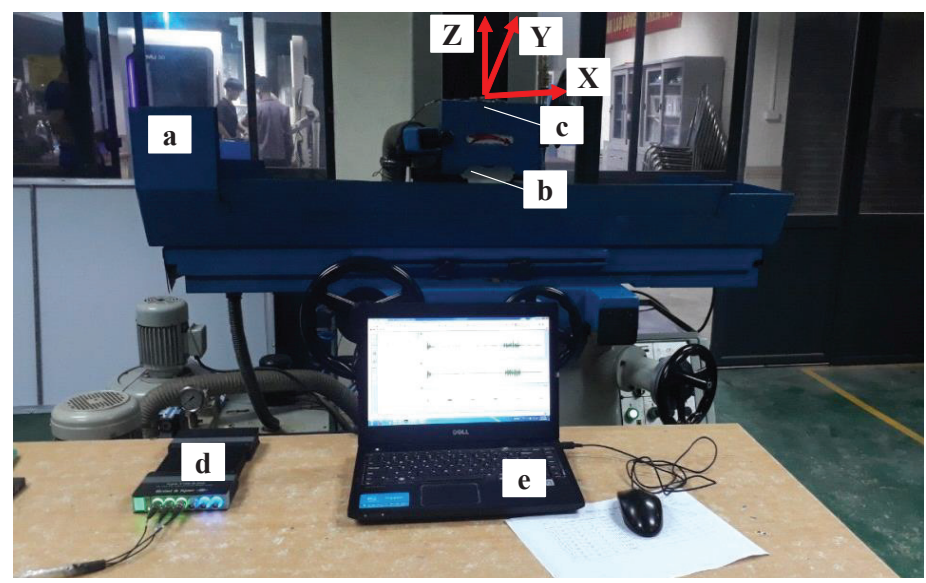

Fig. 3. Setup of vibration measurement: $a$-grinding machine; $b$-grinding wheel; $c$-aceleration sensor; $d$-data processing box; $e-\mathrm{PC}$ and software

\section{5. Machining Condition}

The experiments were conducted in the grinding conditions as following:

- Grinding wheel velocity: $26 \mathrm{~m} / \mathrm{s}$.

- Cooling fluid: emulsion $10 \%$, overflow irrigation method, volume flow rate of $5 \mathrm{lit} / \mathrm{min}$. 


\section{Results and discussions}

The experiments were conducted according to the Table 4. The experimental results were achieved and stored in Table 5. The influence degrees of the input parameters (groove number on the cylinder grinding surface, workpiece velocity, feed-rate, cutting depth) on the output parameters (machining surface roughness, vibration amplitudes in $X, Y, Z$ directions) were presented from Fig. 4-7.

Table 5

Experimental matrix and Results

\begin{tabular}{ccccccccc}
\hline No. & $\boldsymbol{Z}$ (grooves) & $\boldsymbol{V}(\mathbf{m} / \mathbf{m i n})$ & $\boldsymbol{f}(\mathbf{m m} / \mathbf{s t r})$ & $\boldsymbol{t}(\mathbf{m m})$ & $\boldsymbol{R} \boldsymbol{a}(\boldsymbol{\mu m})$ & $\boldsymbol{A x}(\boldsymbol{\mu m})$ & $\boldsymbol{A y}(\boldsymbol{\mu m})$ & $\boldsymbol{A z}(\boldsymbol{\mu m})$ \\
\hline 1 & 15 & 10 & 2 & 0.005 & 0.537 & 0.3578 & 1.2138 & 0.3601 \\
2 & 15 & 15 & 3 & 0.010 & 1.198 & 0.6676 & 2.4796 & 0.7057 \\
3 & 15 & 20 & 4 & 0.015 & 1.542 & 0.7484 & 6.2027 & 1.6251 \\
4 & 18 & 10 & 3 & 0.015 & 0.656 & 0.7042 & 2.0370 & 0.8476 \\
5 & 18 & 15 & 4 & 0.005 & 1.133 & 0.7347 & 2.0523 & 0.9499 \\
6 & 18 & 20 & 2 & 0.010 & 1.001 & 0.4356 & 1.5205 & 0.4845 \\
7 & 20 & 10 & 4 & 0.010 & 1.983 & 1.8158 & 5.7678 & 1.9608 \\
8 & 20 & 15 & 2 & 0.015 & 2.095 & 0.9331 & 2.8419 & 1.3573 \\
9 & 20 & 20 & 3 & 0.005 & 2.543 & 0.5943 & 1.4069 & 0.7439
\end{tabular}

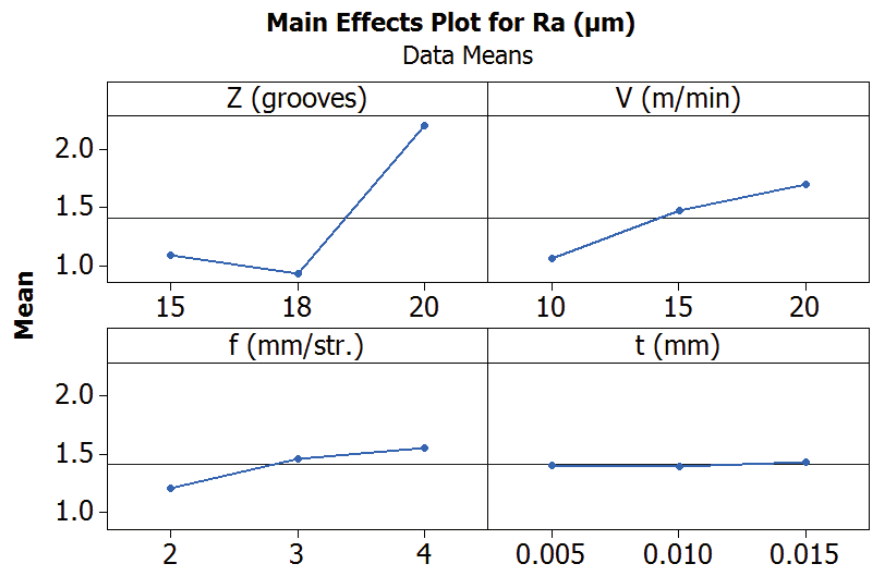

Fig. 4. Main Effect Plot for Ra

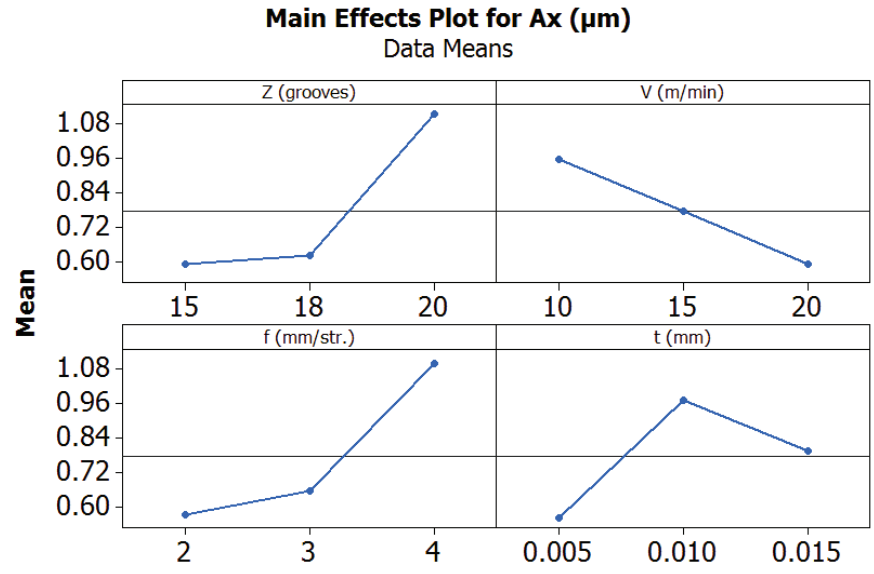

Fig. 5. Main Effect Plot for Ax 


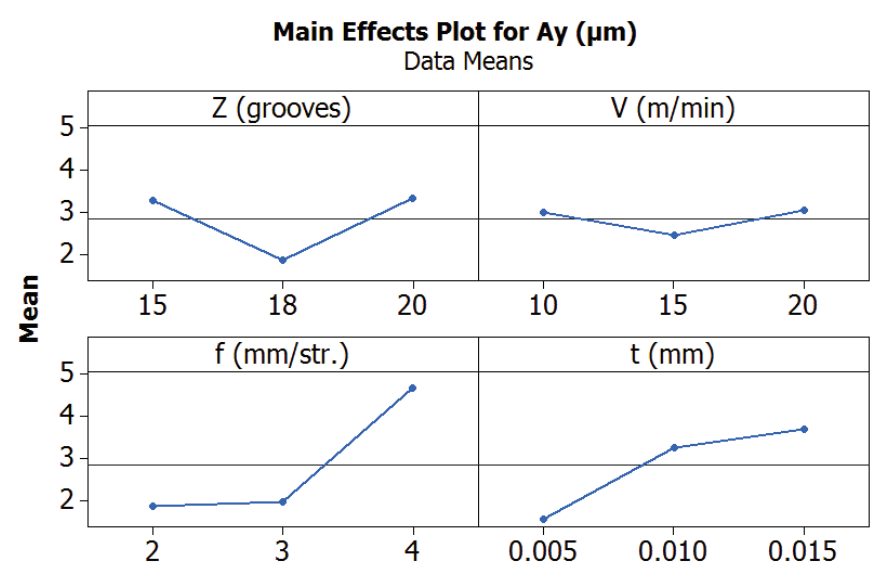

Fig. 6. Main Effect Plot for Ay

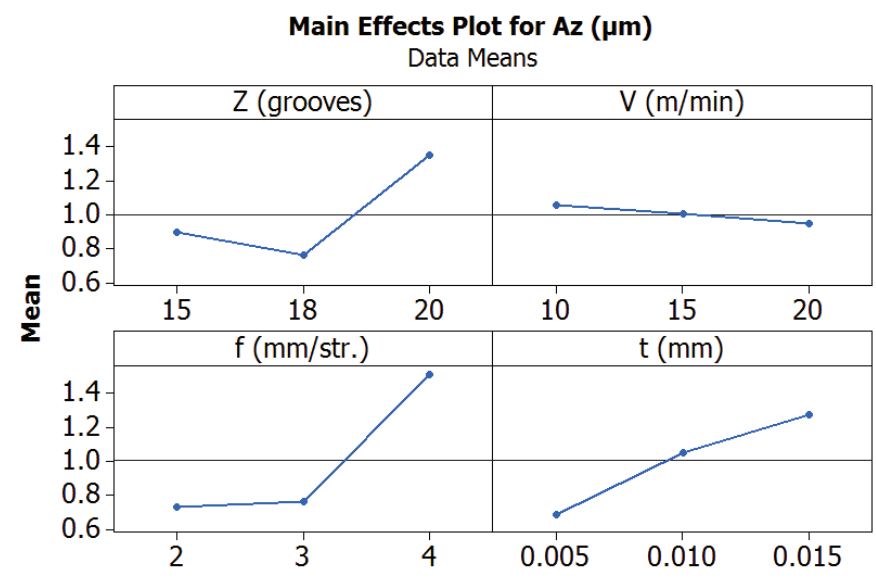

Fig. 7. Main Effect Plot for Az

The results from these figures showed that:

- the number of grooves on the cylinder surface of grinding wheel had the most influence on the machining surface roughness. This issue can be explained that when the number of the grooves changes, it makes the changes of the friction between grinding wheel and workpiece surface. It changes the level of coolant introduction into the cutting zone and also changes the chip release and heat release ability during machining. These factors change the degree of scratching of the grinding grains on the workpiece surface and change the plastic deformation on the workpiece surface, so changing the surface roughness;

- the second factor that influenced on the machining surface roughness was workpiece velocity. This phenomenon can be explained as following: when the workpiece speed changes, it will change the contact time between the workpiece surface and the grinding wheel, which changes the number of scratches of the grinding grains into the workpiece surface leading to change of surface roughness. The feed-rate and the depth of cut had a little effect on the surface roughness;

- all four input parameters that had a significant influence on the amplitude of the technology system's vibration in the $X$-direction. In which, it seems that the degrees of influence on the vibration amplitude in $X$ direction increased in the order of influence of cutting depth, workpiece velocity, number of grooves, and feed-rate. This phenomenon can be explained as following: when changing the number of grooves in the grinding wheel as well changing the cutting parameters, the cutting conditions of grinding wheel into the workpiece will change, therefore influencing on the cutting force and vibration degree of the system in $X$ direction;

- the feed-rate had the most influence on the system vibration amplitude in $Y$ direction. The second factor that affected on the system vibration amplitude in $Y$ direction was depth of cut. The number of grooves on the cylinder surface of grinding wheel and the workpiece velocity had 
a little effect on the system vibration amplitude in $Y$ direction. The feed-rate also had the most influence on the system vibration amplitude in $Z$ direction. The second and third factors that affected on the system vibration amplitude in $Z$ direction were also depth of cut and number of grooves on the cylinder surface of grinding wheel. The workpiece velocity also had a little effect on the system vibration amplitude in $Z$ direction. The reason is because when changing the feed rate, it will change the «re-cut» phenomenon of the grinding wheel into the workpiece surface. While changing the cutting depth will change the depth of the cut of each grinding grain left on the workpiece surface, this will also change the «re-cut» phenomenon. These factors change the cutting forces and vibrations in the $Y$-direction;

- when using grinding wheel with 18 grooves, the machining surface roughness, $A y$, and $A z$ were smallest in comparing with the cases using grinding wheel with 15 and 20 grooves. Besides, when using grind wheel with 18 grooves, $A x$ was larger than that one when using grinding wheel with 15 grooves, but it was smaller than that one when using grinding wheel with 20 grooves. It seems that the machining surface roughness and vibration amplitudes will be obtained with small values when using the grinding wheel with 18 grooves. This problem can be understood because changing the number of grooves on the grinding wheel surface will change the contact conditions between the grinding wheel and the workpiece and change the coolant supply degree into the cutting zone, change the chip escaping phenomenon and heat escaping phenomenon when grinding, so these phenomena will influence on the plastic deformation of the machining surface, thereby affecting surface roughness and vibrating components;

- when the workpiece velocity increased, the machining surface roughness increased, but the $A x$ decreased. The workpiece velocity almost had not the influence on the $A y$ and $A z$. This point can be explained that the reason for the value of $A x$ decreased in higher workpiece velocity would be that the higher load in $X$ direction increases the apparent rigidity. This factor had a litter effect on the vibrations in the other directions ( $Y, Z$ directions);

- when increasing the feed-rate, the vibration amplitude $(A x)$ increased quickly. While $A y$ and $A z$ only increased when the feed-rate increased from $3 \mathrm{~mm} /$ stroke to 4 strokes. This is easy to understand because when the feed rate increases, in the next longitudinal stroke, the grinding wheel will have to perform the «re-cutting» process the protrusions on the workpiece surface more than the previous stroke. This causes cutting forces and vibration components to increase;

- when depth of cut increased, the vibration amplitudes in $Y$ and $Z$ directions ( $A y$ and $A z$ ) increased. While $A x$ only increased when the depth of cut increased from $0.005 \mathrm{~mm}$ to $0.01 \mathrm{~mm}$. If the cutting depth increased from $0.01 \mathrm{~mm}$ to $0.015 \mathrm{~mm}, A x$ decreased. The reasons for these influence is understood that when the depth of the cut changes, the depth of the cuts of the grinding grains left on the workpiece surface change, it also changes the degree of plastic deformation of the machined materials, thereby alter cutting forces and vibrating components.

From above points of analyzed results, it seems that the degree and rule of input parameters on the machining surface roughness, system vibration amplitudes were quite complex. To determine the input parameters with minimum values of surface roughness and system vibrations, the multi-objective optimization problem should be solved. Four output parameters that were machining surface roughness, vibration amplitude in $X, Y, Z$ directions were chosen as the objective functions of the multi-objective optimization problem. In this study, DEAR technique was used to solve this problem.

From the results in Table 5, the weight of each response and MRPI at each experiment were calculated and stored in Table 6. From the date in Table 6, MRPI of all input parameters that were calculated by sum of MRPI of each parameter at the corresponding level and stored in Table 7.

The results from Table 7 showed that the number of grooves on the cylinder surface of grinding wheel and workpiece velocity had the smallest values of MRPI corresponding to the level 2. While the feed-rate and depth of cut had the smallest values of MRPI corresponding to the level 1. So, the optimum values of the input parameters that were groove numbers of 18 ( $Z=18$ grooves), workpiece velocity of $15 \mathrm{~m} / \mathrm{min}(V=15 \mathrm{~m} / \mathrm{min})$, feed-rate of $2 \mathrm{~mm} /$ stroke ( $f=2$ stroke), and cutting depth of $0.005 \mathrm{~mm}(t=0.005 \mathrm{~mm})$. The MRPI had the largest value of Max-Min was the feedrate $($ Max-Min $=3.69445)$. So, if evaluating the grinding process through the grinding surface roughness, system vibrations in $X, Y, Z$ directions, feed-rate was factor that has the most influence 
on the output parameters, the second and third factor that have the effect on the output parameter were number of grooves and depth of cut. The workpiece velocity has the smallest influence on the output parameters. These results were suitable with the analyzed results that were presented in above sections 3 .

Table 6

The respones weight and $M R P I$ at each experiment

\begin{tabular}{cccccc}
\hline \multirow{2}{*}{ No. } & \multicolumn{2}{c}{ Weight } & \multicolumn{1}{c}{ M } & MRPI \\
\cline { 2 - 5 } 1 & $\boldsymbol{R} \boldsymbol{A}$ & 0.05118 & 0.04756 & 0.03986 & 0.11312 \\
2 & 0.04232 & 0.09549 & 0.09715 & 0.07811 & 0.47289 \\
3 & 0.09442 & 0.10704 & 0.24303 & 0.17987 & 2.06725 \\
4 & 0.12153 & 0.10072 & 0.07981 & 0.09381 & 0.34694 \\
5 & 0.05170 & 0.10508 & 0.08041 & 0.10514 & 0.44328 \\
6 & 0.08930 & 0.06230 & 0.05957 & 0.05363 & 0.22268 \\
7 & 0.07889 & 0.25972 & 0.22599 & 0.21703 & 2.51051 \\
9 & 0.15629 & 0.13346 & 0.11135 & 0.15023 & 0.99080 \\
9 & 0.16512 & 0.08500 & 0.05512 & 0.08234 & 0.69900
\end{tabular}

Table 7

Total values of MRPI of the input parameters at the levels

\begin{tabular}{ccccc}
\hline \multirow{2}{*}{ Parameters } & \multicolumn{3}{c}{ Levels } & Max-Min \\
\cline { 2 - 4 } & $\mathbf{1}$ & $\mathbf{2}$ & $\mathbf{3}$ & 3.18742 \\
\hline$Z$ & 2.65326 & $\mathbf{1 . 0 1 2 8 9}$ & 4.20032 & 1.08197 \\
$f$ & 2.97057 & $\mathbf{1 . 9 0 6 9 6}$ & 2.98893 & $\mathbf{3 . 6 9 4 4 5}$ \\
$t$ & $\mathbf{1 . 3 2 6 5 9}$ & 1.51883 & 5.02105 & 2.14960
\end{tabular}

To verify the results of the optimization process, several tests were carried out in the same technology system. The optimum values of input parameters that were used in grinding tests were groove numbers of 18 grooves, workpiece velocity of $15 \mathrm{~m} / \mathrm{min}$, feed-rate of $2 \mathrm{~mm} / \mathrm{stroke}$, and cutting depth of $0.005 \mathrm{~mm}$. The obtained values of averages of grinding surface roughness, vibration amplitudes in $X, Y, Z$ directions were $0.826(\mu \mathrm{m}), 0.531(\mu \mathrm{m}), 0.549(\mu \mathrm{m})$, and $0.646(\mu \mathrm{m})$, respectively. These results were great improved in comparing to the experimental results in Table 5.

\section{Conclusion}

In this study, the combination of Taguchi method and DEAR technique that was successfully applied to determine the optimum values for multi-objective when grinding the SAE420 steel by using the segmented grinding wheel. From the achieved results, the conclusions of this study were withdrawn as following:

- the degree and rule of input parameters on the machining surface roughness, system vibration amplitudes were very complex;

- the number of grooves on the cylinder surface of grinding wheel had the most influence on the machining surface roughness. The second factor that influenced on the machining surface roughness was workpiece velocity. The feed-rate and the depth of cut had a little effect on the surface roughness; 
- when using grinding wheel with 18 grooves, the machining surface roughness, $A y$, and $A z$ were smallest in comparing with the cases using grinding wheel with 15 and 20 grooves. Besides, when using grinding wheel with 18 grooves, $A x$ was larger than that one when using grinding wheel with 15 grooves, but it was smaller than that one when using grinding wheel with 20 grooves;

- feed-rate was factor that has the most influence on the output parameters, the second and third factor that have the effect on the output parameter were number of grooves and depth of cut. The workpiece velocity has the smallest influence on the output parameters;

- the optimum values of input parameters were groove number of 18 grooves, workpiece velocity of $15 \mathrm{~m} / \mathrm{min}$, feed-rate of $2 \mathrm{~mm} /$ stroke, and cutting depth of $0.005 \mathrm{~mm}$;

- using the optimum values of input parameters, averages value of grinding surface roughness, vibration amplitudes in $X, Y, Z$ directions were $0.826(\mu \mathrm{m}), 0.531(\mu \mathrm{m}), 0.549(\mu \mathrm{m})$, and $0.646(\mu \mathrm{m})$, respectively. These results were great improved in comparing the cases using the normal values of input parameters;

- taguchi method and DEAR technique can be applied to improve the quality of grinding surface and reduce the vibrations of the technology system. So that can be used to restrain the increasing of the cutting forces and chatter in the grinding process;

- in this study, only the number of grooves in the grinding wheel is considered, have not considered the size and shape of the grooves. Besides, other factors of the grinding process affect the output parameters such as grinding wheel dressing, cooling lubrication conditions, etc. also have not considered in this study. These are issues that need to be done in the next research to evaluate the segmented grinding wheel process in a more comprehensive way.

\section{References}

[1] Herman, W. C. (1936). Pat. No. US2032362A. Segmental grinding wheel. Available at: https://patents.google.com/patent/ US2032362A/en

[2] Nguyen, T., Zhang, L. C. (2005). Modelling of the mist formation in a segmented grinding wheel system. International Journal of Machine Tools and Manufacture, 45 (1), 21-28. doi: https://doi.org/10.1016/j.ijmachtools.2004.06.019

[3] Lee, K. W., Wong, P. K., Zhang, J. H. (2000). Study on the grinding of advanced ceramics with slotted diamond wheels. Journal of Materials Processing Technology, 100 (1-3), 230-235. doi: https://doi.org/10.1016/s0924-0136(00)00403-9

[4] Jin, D. X., Meng, Z. (2004). Research for Discontinuous Grinding Wheel with Multi-Porous Grooves. Key Engineering Materials, 259-260, 117-121. doi: https://doi.org/10.4028/www.scientific.net/kem.259-260.117

[5] Fan, X., Miller, M. (2004). Force Analysis for Segmental Grinding. Proc ASPE Annual Meeting, 3-6.

[6] Handigund, P. B., Miller, M. H. (2011). Abrasive Wear and Forces in Grinding of Silicon Carbide. Michigan Technological University. Houghton, MI.

[7] Phuong, N. T., Giang, N. T. P., Dong, N. T. (2017). Research on the Affect of Technologycal Parameters on Cutting Temperature When Machining use Segmented Grinding Wheel. International Journal of Electronics Communication and Computer Engineering, 8 (3), 208-212.

[8] Phuong, N. T., Nguyen, G. P. T., Nguyen, D. T. (2017). A research on the effect of cuttıng parameters on cuttıng force in flat grındıng usıng segmented grındıng wheel. Vietnam Journal of Science and Technology, 55 (6), 793-802. doi: https:// doi.org/10.15625/2525-2518/55/6/8961

[9] Ohashi, K., Tan, K., Ashida, T., Tsukamoto, S. (2015). Quick On-Machine Measurement of Ground Surface Finish Available for Mass Production Cylindrical Grinding Processes. International Journal of Automation Technology, 9 (2), $176-183$. doi: https://doi.org/10.20965/ijat.2015.p0176

[10] Takaya, Y. (2014). In-Process and On-Machine Measurement of Machining Accuracy for Process and Product Quality Management: A Review. International Journal of Automation Technology, 8 (1), 4-19. doi: https://doi.org/10.20965/ijat.2014.p0004

[11] Nguyen, N.-T., Kao, Y.-C., Dung, H. T., Trung, D. D. (2020). A Prediction Method of Dynamic Cutting Forces and Machine-Tool Vibrations When Milling by Using Ball-End Mill Cutter. Lecture Notes in Networks and Systems, 47-54. doi: https://doi.org/10.1007/978-3-030-37497-6_5

[12] Nguyen, T.-L., Nguyen, N.-T., Hoang, L. (2020). A study on the vibrations in the external cylindrical grinding process of the alloy steels. International Journal of Modern Physics B, 34 (22n24), 2040150. doi: https://doi.org/10.1142/s0217979220401505

[13] Marinescu, I. D., Hitchiner, M. P., Uhlmann, E., Rowe, W. B., Inasaki, I. (2006). Handbook of Machining with Grinding Wheels. CRC Press, 632. doi: https://doi.org/10.1201/9781420017649

[14] Malkin, S., Guo, C. (2008). Grinding technology: Theory and Applications of Machining with Abrasives. Industrial press, 372. 
[15] Cao, Y., Guan, J., Li, B., Chen, X., Yang, J., Gan, C. (2013). Modeling and simulation of grinding surface topography considering wheel vibration. The International Journal of Advanced Manufacturing Technology, 66 (5-8), 937-945. doi: https:// doi.org/10.1007/s00170-012-4378-7

[16] Malkin, S. (1984). Grinding of metals: Theory and application. Journal of Applied Metalworking, 3 (2), 95-109. doi: https:// doi.org/10.1007/bf02833688

[17] Aini, R., Rahnejat, H., Gohar, R. (1990). A five degrees of freedom analysis of vibrations in precision spindles. International Journal of Machine Tools and Manufacture, 30 (1), 1-18. doi: https://doi.org/10.1016/0890-6955(90)90037-j

[18] Liu, T., Deng, Z., Lv, L., She, S., Liu, W., Luo, C. (2020). Experimental Analysis of Process Parameter Effects on Vibrations in the High-Speed Grinding of a Camshaft. Strojniški Vestnik - Journal of Mechanical Engineering, 66 (3), 175-183. doi: https:// doi.org/10.5545/sv-jme.2019.6294

[19] Phadke, S. (1989). Quality Engineering Using Robust Design. Prentice Hall, 250.

[20] Karna, S. K., Singh, R. V., Sahai, R. (2012). Application of Taguchi Method in Indian Industry. International Journal of Emerging Technology and Advanced Engineering, 2 (11), 387-391.

[21] Karna, S. K., Sahai, R. (2012). An Overview on Taguchi Method. International Journal of Engineering and Mathematical Sciences, 1, 11-18.

[22] Manoj, M., Jinu, G. R., Muthuramalingam, T. (2018). Multi Response Optimization of AWJM Process Parameters on Machining TiB2 Particles Reinforced Al7075 Composite Using Taguchi-DEAR Methodology. Silicon, 10 (5), $2287-2293$. doi: https://doi.org/10.1007/s12633-018-9763-x

[23] Muthuramalingam, T., Vasanth, S., Vinothkumar, P., Geethapriyan, T., Rabik, M. M. (2018). Multi Criteria Decision Making of Abrasive Flow Oriented Process Parameters in Abrasive Water Jet Machining Using Taguchi-DEAR Methodology. Silicon, 10 (5), 2015-2021. doi: https://doi.org/10.1007/s12633-017-9715-x

[24] Thangaraj, M., Loganathan, G. B., Atif, A., Palanisamy, S. (2019). Multi Response Optimization on Machining Titanium Alloy Using Taguchi-DEAR Analysis in Abrasive Water Jet Cutting. SAE Technical Paper Series. doi: https://oi.org/ 10.4271/2019-28-0070

[25] Sandeep, M. J., Manjunath, P. G. C., Chate, G. R., Parappagoudar, M. B., Daivagna, U. M. (2019). Multi Response Optimization of Green Sand Moulding Parameters Using Taguchi-DEAR Method. Applied Mechanics and Materials, 895, 1-7. doi: https://doi.org/10.4028/www.scientific.net/amm.895.1

[26] Reddy, V., Reddy, C. S. (2016). Multi Response Optimization of EDM of AA6082 Material using Taguchi- DEAR Method. International Journal of Scientific \& Engineering Research, 7 (6), 215-219.

[27] Muthuramalingam, T., Vasanth, S., Mohamed, R. M., Geethapriyan, T., Ramamurthy, A. (2016). Multi reponse Optimization of EDM Process Parameters using Assignments of Weight Method. International Journal of Engineering Research \& Technology, 4 (26). 